\title{
LA ICONOGRAFÍA DEL NEFESH EN LA PLÁSTICA PÚNICA: A PROPÓSITO DE LAS REPRESENTACIONES DEL MONUMENTO FUNERARIO Y SU SIGNIFICADO ${ }^{1}$
}

\author{
POR \\ FERNANDO PRADOS MARTÍNEZ \\ Université de Toulouse II - Le Mirail ${ }^{2}$
}

\begin{abstract}
RESUMEN
En el presente trabajo vamos a aproximarnos a una cuestión fundamental en el campo de la iconografía feniciopúnica, dada la relevancia que la representación artística del modelo arquitectónico turriforme conocido como "Nefesh" tuvo en las culturas semitas. Para ello, siguiendo un orden meramente cronológico y a través de algunos ejemplos, estudiaremos la representación de los monumentos en algunas estelas funerarias, en el interior de los sepulcros y en los amuletos, así como el significado que estas representaciones pudieron tener en el marco de la religiosidad y las creencias.
\end{abstract}

\section{SUMMARY}

In the present article, we approach to the knowledge of Phoenician and Punic religious iconography. The artistic representation of an architectonic model called "Nefesh" had very significance in the Semitic cultures. For that, whith many examples, we studied the representation of the Punic towermonuments in some funerary steles, inside the graved and in the charms. This work can be of utility for meet the signification that these representations had in to the religiosity and believes.

PALABRAS CLAVE: iconografía, arte púnico, monumento turriforme, amuletos, pinturas funerarias.

KEY WORDS: Iconography, Punic art, tower monument, charms, funerary paintings.

\section{INTRODUCCIÓN}

En primer lugar, antes de centrarnos en el tema objeto del trabajo, creemos conveniente y oportuno realizar una breve aproximación al estado de la cuestión sobre el

\footnotetext{
1 Este trabajo ha surgido a partir de la realización de nuestra Tesis Doctoral que se centró en la arquitectura funeraria púnica de carácter monumental. Por esta razón y porque es deudor en diversos aspectos de muchas sugerencias realizadas por el Dr. Manuel Bendala, director de la misma, queremos significar públicamente nuestro reconocimiento y expresar desde aquí nuestro agradecimiento.

2 El trabajo se enmarca dentro de un proyecto de investigación postdoctoral financiado por la Secretaría de Estado de Universidades e Investigación del Ministerio de Educación y Ciencia.
}

estudio de los monumentos funerarios púnicos, de cara a facilitar, posteriormente, el desarrollo de la exposición. Se trata de un tema que fue tratado en profundidad hace ya décadas ${ }^{3}$, pero que no ha sido reinterpretado teniendo en cuenta muchos de los datos con los que, gracias al avance de la investigación sobre arquitectura, sobre el mundo de la ideología o la etnicidad, contamos hoy día ${ }^{4}$. La arquitectura monumental es un apartado poco conocido sobre el que, además, parecen haber quedado zanjadas numerosas cuestiones sin reparar en que el propio avance de la investigación y la mejora del conocimiento sobre la cultura púnica han variado en gran medida las interpretaciones tradicionales que aún siguen siendo aceptadas por la comunidad científica. Entre esas cuestiones están las de interpretar los monumentos como mausoleos (por ejemplo, Rakob, 1979; Gamer, 1982; Stucchi, 1987; Toynbee, 1993) o adscribir los edificios siempre al campo cultural helenístico, derivados de un modelo matriz generado en Halicarnaso (Mansuelli, 1963; Coarelli y Thébert, 1988), cuando hoy sabemos que muchos de éstos eran estructuralmente macizos, no contenían ninguna cámara funeraria y ni siquiera señalizaron la existencia de un hipogeo excavado debajo, además de fecharse -los más antiguos- a finales del siglo $\mathrm{V}$ a.C ${ }^{5}$. Evidentemente, los edificios estuvieron cargados por lo general de simbolismo religioso vinculado con la ideología de la muerte, lo que no significó que se tratase siempre de sepulcros (Prados Martínez, 2005c, 643).

Sabemos bien que la arquitectura funeraria es la única que ha dejado restos visibles de lo que debió ser la arquitectura monumental púnica, al no haber quedado

3 Cid Priego, C., 1949; Almagro Gorbea, M., 1982 o Coarelli, F. y Thébert, Y., 1988.

4 Prados Martínez, F., 2005 b.

5 El desarrollo de la investigación sobre los grandes monumentos helenísticos como el Mausoleo de Halicarnaso y la corriente filohelena en la que se vio inmersa buena parte de la comunidad científica a lo largo del siglo XX provocó que, durante décadas, se plantease este conocido edificio como el modelo primigenio a imitar. Evidentemente, ni las cronologías ni la propia estructura de templo-tumba del Mausoleo permiten hoy defender esta hipótesis. 
en pie restos de construcciones de cierta entidad, aparte de las fortificaciones. Esta es una de las principales razones por las que muchos investigadores se han aproximado al estudio de la arquitectura funeraria $-\mathrm{y}$ dentro de ésta, a la de carácter turriforme- como el único vehículo para reconocer lo que debieron ser las manifestaciones constructivas de la gran "madre mediterránea", de la megalópolis que dominó el mar durante tres siglos. Así se reconocieron estos edificios como los sepulcros de los grandes personajes reales, de las grandes figuras históricas de las que nos hablan las fuentes (Krandel, 2002).

Hasta hace poco se pensaba que los monumentos turriformes eran más propios de la cultura númida que de la púnica, ya que los grandes edificios conocidos (Dougga, Sabratha, Siga o la Sôuma de Khroub) se ubicaban lejos de Cartago, en zonas de una profunda raigambre cultural indígena ${ }^{6}$. El principal problema era que muchos de los hipogeos púnicos mostraban en sus decoraciones pictóricas la representación de estos modelos arquitectónicos, lo que no encajaba con la ausencia de los mismos en las proximidades, apreciación ésta que ya había sido señalada por algunos (Fantar, 1988). La cuestión es que en los últimos años, gracias a la realización de las prospecciones de la Carta Arqueológica de Túnez ${ }^{7}$ y la relectura de los informes de las antiguas misiones francesas e italianas efectuadas a lo largo del siglo XIX con la intención de cartografiar el territorio ${ }^{8}$, la situación ha cambiado y los grandes huecos vacíos ubicados alrededor de la capital púnica se han ido llenando paulatinamente de puntos que señalan la ubicación de monumentos como tal (El Haouam, Ksar Chenane, Ksar Rouaha, Henchir Bourgou) o restos monumentales pertenecientes a edificios casi perdidos (como por ejemplo Ksar Bou Derhem en la región de Hédils o Uzali Sar en Henchir Djal, del que se recuperaron sillares, fragmentos de la cornisa en forma de gola y una escultura que representaba una sirena ${ }^{9}$ ). Estos hallazgos y los muchos que aún permanecen inéditos conllevan un cambio en la adscripción cultural y étnica de la arquitectura turriforme al tiempo que provocan que la interpretación positivista centrada en identificar los "mausoleos" con los sepulcros de los grandes personajes quede por fin relegada a un segundo plano.

6 Tesis defendida por investigadores como F. Rakob (Rakob, F., 1979, 119-171)

7 Realizada por el Institut National du Patrimoine de Túnez bajo la dirección de S. Ben Baaziz y publicada en la serie Atlas Préhistorique de la Tunisie, Tunis.

8 Babelon, E.; Cagnat, R. y Reinach, S., 1892; Cagnat, R. y Merlin, A., 1914-1926; Cagnat, R. y Reinach, S., 1886 y Deyrolle, E., 1903. Sobre la expedición italiana del Conde Borgia: Poinssot, C. y Salomonson, J.W., 1963.

9 Ferchiou, N., 1988, 216-217
Pero, como se observará a lo largo de estas páginas, los monumentos son mucho más; no sólo fueron construcciones de envergadura que recordaban y heroizaban al difunto o a su familia, ayudando a la redención de su alma a través de un "cambio de esfera" en el cosmos: también aseguraban la aspiración del individuo a alcanzar la salvación, pasando de un registro terrenal a uno superior. Por esta razón, aparecieron decorando el interior de los sepulcros y por eso se fabricaron amuletos y colgantes con su forma o se tallaron en los frontones de las clásicas estelas funerarias. Así pues, el monumento turriforme arquitectonizó una idea (la idea de salvación) y, posteriormente, el modelo arquitectónico desarrollado se convirtió en un símbolo -a escala- de esa misma idea.

Esa es la cuestión que queremos tratar en estas páginas; observar un modelo arquitectónico que, como se verá a continuación, se transformó en un símbolo religioso vinculado con la salvación y con la protección del alma, como uno más de los significados que tuvieron estos edificios de una naturaleza eminentemente polisémica, auténticos hitos geográficos vinculados con la muerte y la religión pero al mismo tiempo símbolos de poder y de prestigio.

\section{EL NEFESH EN EL MARCO DE LA IDEOLO- GÍA Y LA RELIGIOSIDAD PÚNICAS}

En la cultura fenicia y púnica, como en otras tantas de la antigüedad mediterránea, se aprecian en las manifestaciones materiales de credo esotérico y escatológico los esfuerzos que realizaron los creyentes que aspiraron a la consecución de una "salvación individual". En el presente trabajo, a través de una serie de hipótesis y propuestas interpretativas, se analizan diversos aspectos relacionados con la ideología de la muerte y del más allá en el mundo fenicio y púnico y el reflejo de la misma en las representaciones artísticas realizadas en los sepulcros, tanto en el interior como en el exterior de los mismos, así como en los amuletos y demás objetos de adorno personal vinculados con el ajuar funerario. Se trata de una lectura de las decoraciones y de los objetos y su vinculación con la salvación de las almas y con el clásico enfoque doctrinal semita.

Los monumentos turriformes o Nefesh (np̌̌), cuya representación iconográfica abordamos concretamente en este estudio, con su arquitectura vertical compuesta de un basamento escalonado, una estructura cuadrangular generalmente maciza y un remate piramidal, fueron uno de los vehículos principales para el "peregrinaje de las almas" desde la tierra, cuando éstas se liberaban de su prisión corporal y ascendían hasta el mundo astral. Sólo ascendiendo y cruzando el océano superior podrían purificarse para aspirar a la inmortalidad. De todo este proceso nos informan los distintos programas iconográficos representados en los monumentos: por ejemplo, la apari- 
ción dentro de estos programas que decoran los monumentos de seres tales como sirenas -tal y como sucede en el caso de los monumentos púnicos de Uzali Sar y Dougga (Túnez)- deriva de prototipos próximo-orientales y, a través de esta representación, éstas, unen su significado de guardianas de las tumbas (valor apotropaico) con la de vehículos para el transporte del alma del difunto (valor psicopompo). Las sirenas, que mezclan rasgos físicos humanos -femeninos- con otros propios de aves, están asociados generalmente a los espacios funerarios en toda la cuenca mediterránea (Izquierdo, 1999; Walter, 2003) aparecen vinculadas también a los ritos de paso, representadas a menudo cantando y llorando sobre las tumbas. El propio esquema constructivo de tipo vertical asume, en sí mismo, el papel de vehículo conductor del alma. No olvidamos, por otro lado, otras características funcionales que el monumento tuvo también: se trató de un señalizador territorial y fronterizo, un hito en el paisaje y una tumba en algún caso con un doble lenguaje, tanto de señalizador externo como de personificación del allí enterrado u homenajeado, de cara a permitir su comunicación con los vivos. Todos estos significados del monumento turriforme son fácilmente demostrables pero, en el caso que nos ocupa, tan sólo queremos reseñar su papel ideológico-religioso, es decir, su función como vehículo que acerca el alma del difunto al cielo, permitiéndole alcanzar su lugar entre los inmortales, ya que es éste el aspecto sobre el que se incide especialmente en la iconografía que lo representa y que es objeto de estas páginas.

Fuera de los aspectos decorativos y dentro de los estrictamente arquitectónicos, aunque no por ello menos cargado de simbolismo, hemos de anotar la importancia de la pirámide o piramidium que remata -o remataba- la práctica totalidad de los monumentos (construidos o representados). Se trata de un símbolo en sí mismo, de un icono; la pirámide -mer, en lengua egipcia- alude a un lugar de ascensión ${ }^{10}$. En el mundo egipcio no cabe duda de que las pirámides eran símbolos solares. Una de las razones que se suelen esgrimir en este sentido es la identificación de la pirámide con el ben-ben, la piedra sagrada del templo de Atum en Heliópolis ${ }^{11}$. Esta piedra ha sido relacionada con el pene en erección de Atum, y el vocablo ben-ben con su eyaculación ${ }^{12}$. Así, la pirámide simbolizó un lugar de creación y renacimiento, de ahí que generalmente se coloque el Benu-Ave Fénix- directamente por encima de su cumbre.

${ }^{10}$ Sobre estas cuestiones, remitimos a un reciente trabajo de carácter general: Lehner, M., 2003.

${ }^{11}$ Atum fue el primer dios que se adoró en Heliópolis. Atum es un dios de ultratumba y un principio regenerador.

${ }^{12}$ Según el Texto de las Pirámides, 527, “...Atum es el que se desarrolló, teniendo una erección en Heliópolis. Tomó el pene en su mano para poder alcanzar un orgasmo y nacieron dos hermanos, Shu y Tefnut".
Tanto el ben-ben como la pirámide en sí pueden haber simbolizado también los rayos del sol, porque así han sido representados apareciendo entre las nubes. Los Textos de las Pirámides aluden a los rayos solares como una rampa por la que el monarca ascendía hacia el astro padre (así se explica también el escalonamiento de algunas de las pirámides). Si la piedra ben-ben era cónica, la forma de representarla era mediante una pirámide. Además, la escena de la pirámide rematada con un ave no sólo es habitual en el mundo egipcio: en el ámbito cartaginés tenemos buenos ejemplos de monumentos rematados por estructuras piramidales y aves en la cima ${ }^{13}$.

Toda esta simbología fue recogida en la iconografía púnica del Nefesh, del monumento turriforme, que, como se ha visto, iba cargada de significado religioso vinculado fundamentalmente con la consecución de la salvación y de la inmortalidad. No cabe duda de que, como veremos a lo largo de estas páginas, el Nefesh, en sí mismo, constituyó uno de los símbolos religiosos más importantes y, por lo tanto, era susceptible de ser representado en decoraciones funerarias y en amuletos, aparte lógicamente de ser edificado encima de algunos sepulcros.

Pero antes de detenernos en los aspectos puramente iconográficos, objeto de este trabajo, vamos a acercarnos, de una manera sucinta, a las creencias fenicio-púnicas en la inmortalidad y en la dualidad del alma, a las que, como veremos, va unida la representación de un modelo arquitectónico que significa, al mismo tiempo, la arquitectonización de la idea del alma y la sustitución de ese modelo, cargado de simbolismo, por su plasmación artística, tanto pictórica como escultórica u originada en el ámbito de las artes menores.

\section{NEFESH VS ROUAH: LA DUALIDAD DEL ALMA EN LA RELIGIOSIDAD SEMITA}

A partir de la traducción de textos orientales, fundamentalmente ugaríticos y hebreos, se han podido reconstruir algunos de los aspectos más importantes de la cultura fenicia, y dentro de ésta, han sido vitales para tratar de reconstruir la religión (Ribichini y Xella, 1994) tanto en el campo de las creencias como en el de las manifestaciones religiosas y rituales ${ }^{14}$. Según esta documentación, los semitas occidentales, entre los que se encontraban los fenicios, concebían la existencia de una dualidad

\footnotetext{
13 Por ejemplo, en el caso de los monumentos pintados para decorar las paredes de las tumbas de Jebel Zabouj (Túnez).

${ }^{14}$ Gracias a las tablas cananeas de Ras Shamra (Ugarit) se conocen numerosos ejemplos del ritual cananeo del sacrificio de animales, así como de los ritos funerarios que siempre van unidos a referencias a la inmortalidad del alma.
} 
del alma ${ }^{15}$ que podemos definir como alma y espíritu. Se trata de dos elementos fundamentales que son, a la vez, distintos y coexistentes. Por un lado, existía el Nefesh, el alma vegetativa, que, según se desprende de la traducción de algunos textos, tras el momento del fallecimiento residía eternamente en la tumba. Ésta pudo ser, además, la razón de que se denominase Nefesh a las estelas y a los monumentos que señalizaron en el exterior los sepulcros en los textos semitas (feniciopúnicos, hebreos, ugaríticos, nabateos, etc.). Un claro ejemplo lo tenemos en el libro bíblico del Génesis, cuando los hijos de Raquel dedicaron a su madre un monumento funerario -npš- para que fuese eternamente recordada:

“...Y aconteció que al salírsele el alma (pues murió), llamó su nombre Benoní (hijo de mi tristeza) más su padre lo llamó Benjamín (hijo de la mano derecha).

Así murió Raquel, y fue sepultada en el camino de Efrata, la cual es Belén.

Y levantó Jacob un pilar (npš) sobre su sepultura (qbr); ésta es la señal de la sepultura de Raquel hasta hoy ${ }^{16 "}$

Génesis 35, 18-20

El hecho de que el alma vegetativa resida eternamente en el sepulcro supone, además, una serie de condicionantes; por un lado, el sepulcro debe ser respetado, honrado y protegido y ésta es la razón fundamental por la que abundan en los accesos a los mismos fórmulas de maldición ${ }^{17}$, dedicadas a proteger el sepulcro y, por tanto, el alma del difunto, de violaciones o profanaciones. Por otro lado, el Nefesh se identifica, en el interior del cuerpo, con las "entrañas", es decir, con el aparato digestivo. Esta sería una razón más que suficiente para llenar el interior de la tumba de alimentos en el momento de la deposición y de acudir con cierta regularidad a depositar ofrendas junto al acceso al sepulcro ${ }^{18}$. Parece evidente que el alma residente en la tumba debía ser protegida y alimentada. Así se pueden explicar los abundantes elementos cerámicos que aparecen en el interior de los hipogeos portando alimentos (vino, frutas, carnes y pescados).

Volviendo a la dualidad del alma, en oposición al Nefesh estaría el Rouah $^{19}$, que es el alma espiritual, la

\footnotetext{
15 Sobre la dualidad del alma véase: Lods, A., 1906 y Dussaud, R., 1935. Para el mundo púnico: Picard, G., 1957 y la obra de síntesis Archeologia del Inferno (Xella, 1997)

${ }^{16}$ Entre paréntesis aparecen los términos mencionados en la Biblia Hebrea. Trad. Reina-Valera de 1602. Editada por Broadman y Holman (Nashville, 1989).

17 Mazza, F., 1975.

18 Sobre el concepto de Nefesh y su representación en el marco de las tumbas hebreas antiguas véase: Triebel, L., 1999.

${ }^{19}$ Que se puede castellanizar como Ruaj. En el texto hemos querido mantener la nomenclatura francesa, ya que la mayoría de los trabajos que han abordado estas cuestiones están escritos en francés y lo transcriben así directamente del árabe.
}

que abandona el cuerpo en el momento de la muerte, con claras reminiscencias a las creencias básicas orientales. Sabemos de la creencia cartaginesa en el Rouah a través de su mención en la inscripción CIS I, 2785. Como se ha mencionado, Nefesh y Rouah se relacionan, además, con un conjunto de órganos corporales diferentes, que son en los que se manifiestan y con los que se identifican: el Nefesh, como hemos visto, se encuentra en las entrañas; por ejemplo, en un célebre pasaje bíblico del Antiguo Testamento, se da un hecho curioso y que ilustra magníficamente el tema que nos ocupa: el hijo de la viuda de la ciudad fenicia de Sarepta resucita pues su Nefesh, que había salido de las entrañas, vuelve a él:

"Se tendió sobre el niño tres veces y clamó a Yahveh: Dios mío, te ruego hagas volver el alma de este niño a él.

Y Yahveh oyó la voz de Elías, y el alma del niño volvió a él, y revivió"

Reyes I, 17, 21-22

Esto es indicativo, por tanto, de que al Nefesh, como ya hemos visto anteriormente, se le puede alimentar. Existe una cierta autonomía del Nefesh con relación al ser humano y al difunto: un buen ejemplo de ello lo tenemos, de nuevo, en el primer libro bíblico: ahí aparece la manifestación "...que mi Nefesh te bendiga" (Génesis, 27, 23). El Rouah, el alma espiritual, reside, por su parte, en la sangre y en el corazón. Las grandes emociones, vinculadas con el Rouah, es decir, dolor, placer y la pasión, se sienten en los riñones y en el corazón. Otra referencia bíblica es bastante ilustrativa a este respecto; ésta se encuentra recogida en un texto del profeta Jeremías donde relata cómo un grupo de hombres que se encontraban completamente aterrados, se llevaban las manos a los riñones en señal de pánico:

"Inquirid ahora, y mirad si el varón da a luz; porque he visto que todo hombre tenía las manos sobre sus riñones, como mujer que está de parto, y se han vuelto pálidos sus rostros"

Jeremías 30, 6

Otro texto bíblico alude a la existencia de una dualidad del alma, distinguiendo en la traducción castellana entre alma (en este caso, se corresponde con el Nefesh) y espíritu (con el Rouah):

"porque la palabra de Dios es viva y eficaz y más cortante que toda espada de dos filos; y penetra hasta partir el alma y el espíritu..."

Hebreos 4, 12

En esta misma dualidad podemos entender otras referencias bíblicas que aluden a la alimentación de los seres humanos y a la abominación de determinados alimentos que se consideran impuros. Estos capítulos 
bíblicos relatan la prohibición de Yahveh de comer la sangre y las entrañas en general de los animales sacrificados, porque en ellas residía su alma, su vida (por ejemplo, en Génesis 9, 4; Levítico 7, 26; Levítico 17, 10-11; Deuteronomio 12, 16, etc.). Éstas debían siempre ser llevadas a los altares para ser ofrecidas a la divinidad. En efecto, la prescripción lleva implícita el mensaje de prohibición de alimentarse del Nefesh (entrañas) y del Rouah (sangre) de los animales muertos:

“...Si cualquier varón de la casa de Israel o de los extranjeros que moran entre ellos, comiere alguna sangre, yo pondré mi rostro contra la persona que comiere sangre, y la cortaré de entre su pueblo.

Porque la vida está en la sangre y yo os la he dado para hacer expiación sobre el altar por vuestras almas; y la misma sangre hará expiación de la persona"

Levítico 17, 10-11

En resumen, se puede centrar el conocimiento de buena parte de las creencias escatológicas fenicias y púnicas en los dos términos semitas que indicaron la inmortalidad y la dualidad del alma: Nefesh (nps) traducido como alma y como monumento funerario y Rouah (rh) traducido como espíritu o principio vital ${ }^{20}$. De esta forma se vincula a menudo al monumento funerârio con un Nefesh, parte del alma que habita en la tumba tras la muerte y así se le denomina en los textos e inscripciones, mientras que el Rouah, el espíritu, es la parte del alma que asciende al cielo. La intención de la búsqueda de la inmortalidad se refleja en la representación del Rouah que asciende, mientras que el Nefesh queda en la tierra y debe ser honrado -alimentado- y no perturbado, bajo pena de un cruel castigo eterno. La denominación fenicia exacta para el Rouah es Barlat, tal y como se observa en esta inscripción:

$$
\begin{gathered}
\text { npš llhm tpth } \\
\text { brl't lsrm } \\
\text { "su Nefesh se abre al alimento } \\
\text { su barlat (Rouah) a los cánticos" }
\end{gathered}
$$

(Texto ugarítico; Traducción Villeraud, 1931, pág. 355)

En otras inscripciones se observa, por otra parte, que no es el Nefesh la parte del alma que reside en el sepulcro ${ }^{21}$,

\footnotetext{
${ }^{20}$ M.H. Fantar comenta que los púnicos se sirvieron del término Rouah para designar también el soplo vital y que aún hoy en la lengua árabe se encuentra este mismo término bajo una forma muy similar (Fantar, M.H., 1998, 101).

${ }^{21}$ Por ejemplo, en la inscripción funeraria recogida en $K A I$, 214. Otros ejemplos ugaríticos como el recogido en $K T U 1.18$ IV 24- 27 mencionan la separación de alma (Nefesh) y espíritu (Barlat) respecto al cuerpo. Queremos agradecer al profesor F. López Pardo sus indicaciones a este respecto así como otras sugerencias para mejorar el trabajo.
}

sino que también se separa del cuerpo. Estos indicios provocan que quede algo más difusa la identificación del Nefesh con la parte del alma que reside eternamente en el sepulcro y a la que hay que honrar y alimentar. A pesar de ello, contamos con la denominación casi generalizada del monumento como Nefesh, "alma", y no como Rouah, "espíritu”, lo que, según creo, es más que suficiente para defender la idea de la permanencia "terrenal" de una de las dos partes del alma, o, al menos, su identificación directa con el hito que recordará al difunto de manera permanente entre los vivos. En estos casos, el término npš mantiene idéntico significado que los términos msbt o $s k r$, aludiendo a lo que queda del difunto entre la memoria de los vivos (Ribichini, 2004, 51).

En otras muchas ocasiones veremos cómo el monumento funerario se reviste simbólicamente con una iconografía que permitiese asegurar el ascenso del Rouah. En esta iconografía destacan, por lo tanto, las escenas de animales alados (esfinges, sirenas, aves) animales marinos (fundamentalmente peces, delfines y también barcos, en el caso de las decoraciones parietales) y en general criaturas psicopompas que asegurarán llevar a buen término el duro viaje que el alma emprendía ${ }^{22}$. Esta simbología es la que, sin duda, lleva implícita los adornos y representaciones pictóricas que vamos a estudiar a continuación.

\section{LAS REPRESENTACIONES PICTÓRICAS Y ESCULTÓRICAS DE MONUMENTOS TURRI- FORMES}

En este apartado nos vamos a centrar, muy sucintamente, en la representación pictórica y escultórica de los monumentos en el interior y en los accesos de los hipogeos funerarios púnicos. Se trata de un tema ampliamente tratado por la historiografía aunque, salvo en algunos trabajos concretos (Longerstay, 1993; 1995) muchas veces no se ha profundizado en la naturaleza y el significado de tales representaciones, entrando a valorar solamente aspectos descriptivos. La representación del monumento es bastante habitual, aunque la temática es mucho más rica. Destacan las representaciones de frisos geométricos, símbolos religiosos, motivos vegetales y animales, escenas marinas, ciudades y, en algún caso, guerreros y jinetes. Son muchos los complejos funerarios púnicos que presentan estructuras arquitectónicas (altares y monumentos turriformes) entre sus decoracio-

\footnotetext{
${ }^{22}$ Al mismo tiempo estos animales, aparte de tener una clara vinculación con el traslado de las almas, actuaban como acompañantes en la apoteosis del difunto heroizado (acompañándolo en su tránsito).
} 


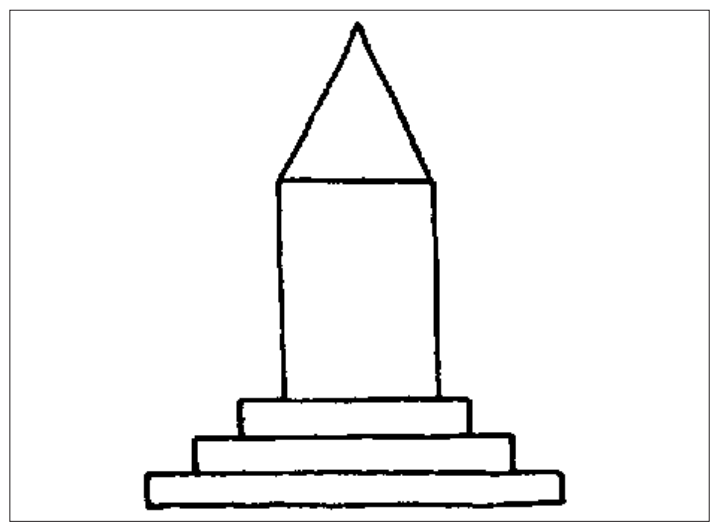

Figura 1. Monumento simple pintado sobre la pared del hipogeo púnico de El Guetma (Túnez). Calco de Longerstay, 1995.

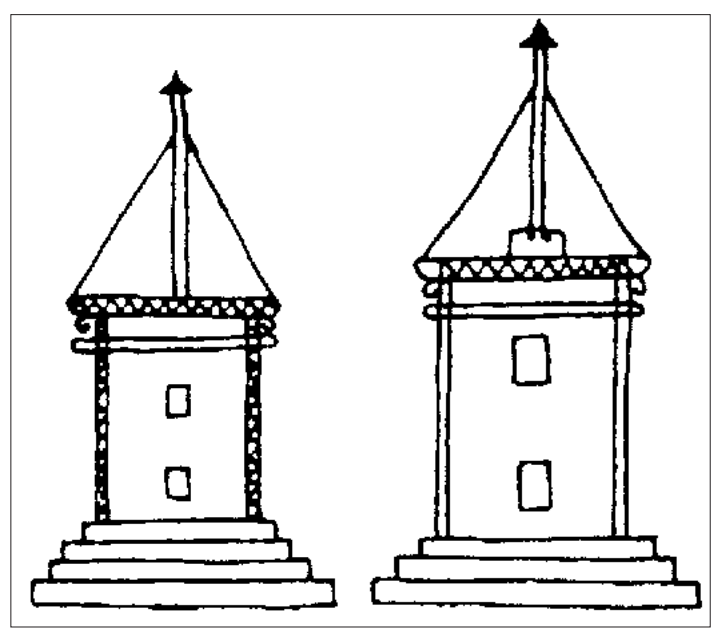

Figura 3. Los dos Nefesh del hipogeo VIII de Jebel Mlezza (Kerkouane, Túnez). Calco de Fantar, 1970.

nes. Estas representaciones no sólo se dan en los ambientes funerarios púnicos; en otras regiones altamente semitizadas aparecen grabados de las mismas características como, por ejemplo, en las jambas de un hipogeo de Khirbat-el'Ein en Judea (Zissu, 2005). Al final de este trabajo hemos incluido un anexo que encierra un corpus en el que se mencionan los hipogeos púnicos y haouanet o tumbas de cámara líbicas que cuentan con monumentos turriformes entre sus decoraciones. La técnica empleada ha sido, mayoritariamente (en más de un $90 \%$ de los ejemplos) la pintura, realizada usando pigmentos naturales como el sulfuro de magnesio, arcillas mezcladas con óxido de hierro y puede que púrpura en algún caso. También en ocasiones los monumentos aparecen grabados con trazos simples sobre las paredes talladas y alisadas de los hipogeos. Las decoraciones pueden aparecer tanto en las paredes laterales o fronta-

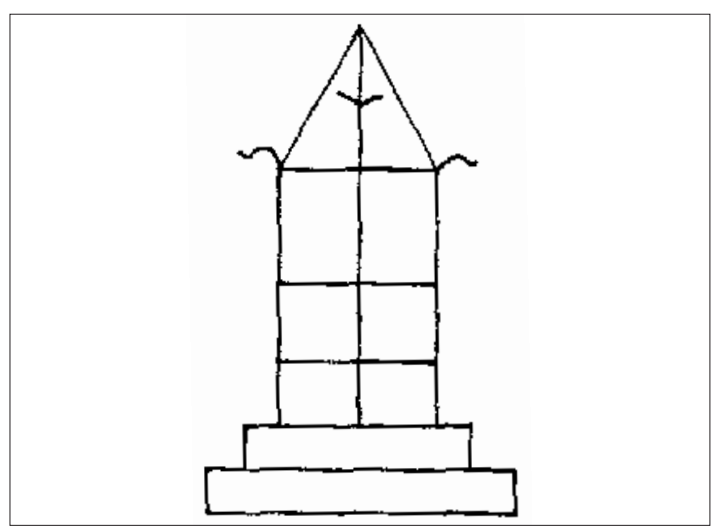

Figura 2. Monumento que decora el interior de la cámara de El Mansourah (Túnez). Calco de Longerstay, 1993.

les de la cámara como en el dintel. Otras veces, como en el caso de la tumba de El-Mansourah, la decoración aparece también en la fachada exterior, sobre el acceso, con la particularidad además de que, en este caso, el monumento encierra un antropónimo (mgnym) acompa-

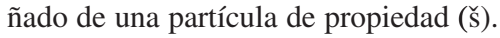

Con los nuevos datos que manejamos hoy día sobre la arquitectura monumental púnica no es necesario acudir a los argumentos ex silentio para justificar la aparición de los monumentos turriformes pintados en las paredes de los hipogeos púnicos y de los hoauanet líbicos ubicados en las proximidades de la ciudad de Cartago, ya que si hace unos años no había resto material de torres en el entorno de la megalopolis, hoy, como sabemos, el panorama se ha modificado tremendamente ${ }^{23}$.

La representación pintada (figs. 1-3) o grabada (figs. 4) de los monumentos en el interior de las cámaras sepulcrales o en sus accesos llevó implícito un mensaje religioso similar al que se observa en otros motivos decorados tales como las aves, los elementos vegetales, los signos astrales y las representaciones de la diosa Tanit. Creemos que con la pervivencia de la representación del monumento junto con otros símbolos relacionados con la salvación en contextos arqueológicos incluso posteriores a la destrucción de Cartago queda suficientemente demostrado el valor sagrado y espiritual del motivo como tal. La vinculación de la representación gráfica del Nefesh con el alma, con la salvación y con

${ }^{23}$ Las prospecciones realizadas en las últimas décadas en los alrededores de la ciudad de Cartago han proporcionado datos suficientes como para defender la existencia de monumentos turriformes en territorio púnico que pudieron servir de modelo a los representados en el interior de las tumbas. Los artistas, por tanto, no debieron desplazarse lejos para tomar los modelos e imitarlos en las paredes de los sepulcros. 


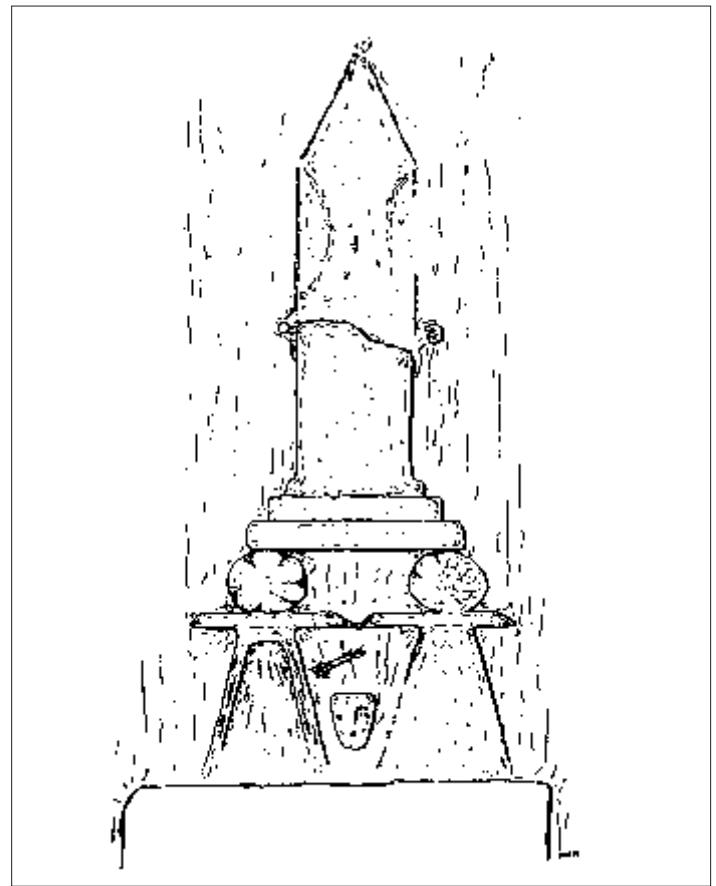

Figura 4. Grabado sobre el dintel de la tumba de Ksar es-Sâad (Sidi Salem, Túnez). Dibujo de Fantar, 2002.

los valores sagrados presentes en la conciencia púnica es muy fuerte. Esta razón nos impide plantearnos hoy el que la pintura de un monumento funerario en la pared de una tumba significase sólo la demostración de la imposibilidad económica de una familia, que tendría que limitarse a pintarlo de no poder construirlo, teoría que ha sido defendida en ocasiones (por ejemplo, Poinssot y Solomonson, 1963). La representación de los monumentos pintados en el interior de los sepulcros ha sido relacionada por los investigadores, generalmente, con los cultos funerarios y con una expresión metonímica del viaje que debía realizar el alma del difunto (Fantar, Longerstay, 1985, 217;) hacia el más allá.

Tampoco creemos que la aparición de estos motivos se debiese al simple trazo de un arquitecto sobre la pared de un monumento para tomarlo como modelo, como se aprecia en el pilar de Monforte del Cid (Alicante) conservado en el Museo Arqueológico de Elche (fig. 5) y que veremos con algo más de detalle a continuación. Si los monumentos turriformes actuaron como vínculos de unión entre dos mundos y representaban, como Nefesh, al difunto entre los vivos, era porque se encontraban bien visibles; pero, por el contrario, en el caso de las representaciones pictóricas o grabadas en el interior de los hipogeos, éstas tuvieron que tener otra función. En estos casos las representaciones fueron símbolos en sí mismas, al igual que el resto de los motivos religiosos que comúnmente aparecieron decorando

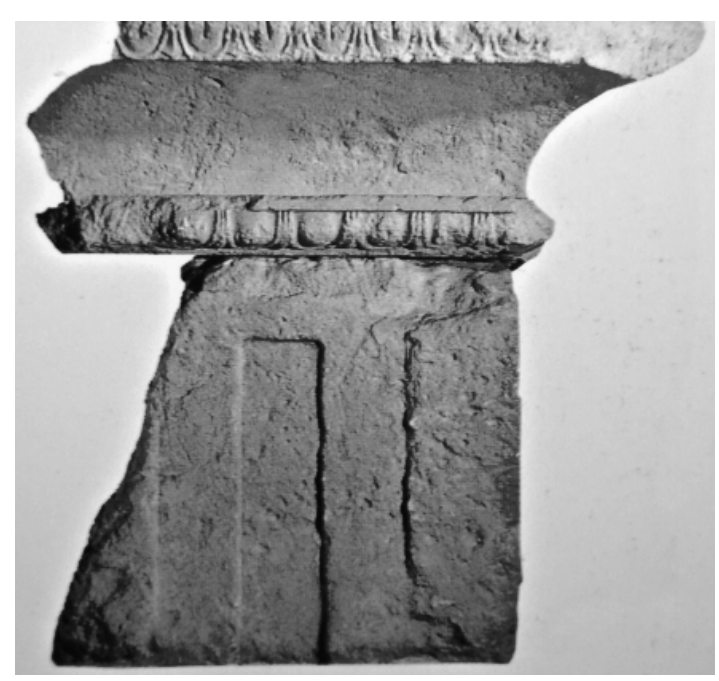

Figura 5. Detalle del pilar-estela de Monforte del Cid, (Alicante).

las paredes de los sepulcros tales como peces, barcos, estrellas, crecientes lunares, signos de Tanit, etc. (figs. 1-4)

Detrás de la plasmación gráfica o plástica (recordemos los amuletos realizados en forma de Nefesh sobre los que trataremos a continuación) del monumento estaba la necesidad de asegurar al máximo posible la consecución de la victoria sobre la muerte y, por tanto, de la vida eterna. Por ello se representó con esta asiduidad la casa del alma, el vehículo de unión entre dos mundos, para que ayudase al difunto a conseguir aquello que ansiaba, fuese materialmente, mediante la arquitectura, simbólicamente, mediante un simple esbozo con cuatro trazos sobre la pared o portándolo como amuleto colgado del cuello. En la representación de ese modelo arquitectónico quedaron reflejadas las creencias más arraigadas y más personales: precisamente aquellas que vinculaban directamente la religión púnica con sus ascendientes orientales, con la concepción de la salvación de los pueblos de Fenicia.

Un buen ejemplo que corrobora esta hipótesis lo tenemos en una estela romana procedente de Cheffia-Tal (conservada en el Museo de Annaba, Argelia) fechada en la primera mitad del siglo I d.C. (fig. 6), ${ }^{24}$ en la que en el frontón que corona el epitafio bilingüe aparecen representados a la misma escala un signo esquemático de Tanit, un creciente lunar, un disco solar y cuatro elementos clásicos relacionados con el traslado del alma al más allá y la victoria sobre la muerte: la corona de laurel, un ave con las alas desplegadas, un caduceo y un monumento funerario. La pieza es un cipo de piedra

\footnotetext{
${ }^{24}$ Stucchi, 1985
} 


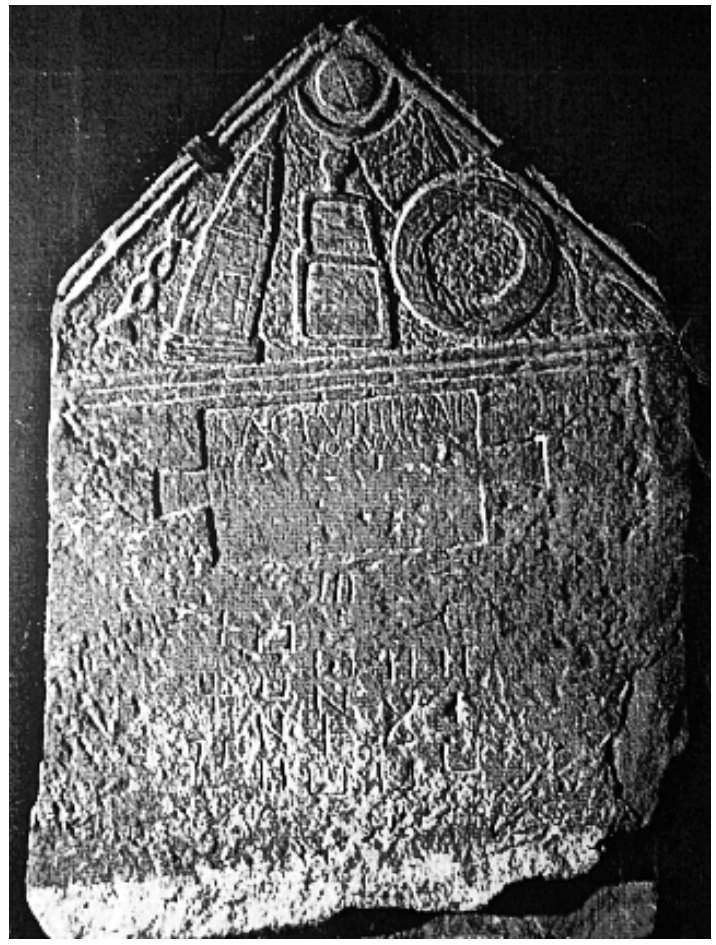

Figura 6. Cipo funerario romano de Cheffia-Tal (museo de Annaba, Argelia). Foto Stucchi, 1985

caliza rosácea terminado en cúspide y la inscripción bilingüe en lengua líbica y en latín aparece enmarcada en una tabula ansata y dice lo siguiente:

\section{SACTVT $\cdot$ IHIMIR \\ F · VIXIT $\cdot$ ANNORVM $\cdot$ LXX \\ Sactut, hijo de Ihimir, vivió 70 años}

(CIL VIII, 5220)

En esta estela funeraria, como veíamos anteriormente, el monumento turriforme, del tipo clásico con cuerpo cúbico sobre basamento escalonado y con falsa puerta decorando la fachada y rematado por un piramidium, se interpreta dentro del mismo lenguaje simbólico que el resto de los elementos: no es la representación de la tumba que no pudo tener el difunto, sino un símbolo de salvación en sí mismo. Además, la estela pertenece a un romano de ascendencia familiar libiopúnica que mantuvo en su estela funeraria vivas tanto su lengua como sus creencias. En ese mismo lenguaje simbólico se inscribe el edificio grabado en la pared del llamado pilar-estela ibérico de Monforte del Cid (figs. 7 y 8) reconstruido hoy en la sala del Museo Arqueológico de Elche (Alicante). Esta representación, que fue publicada en su momento como un modelo o boceto realiza-

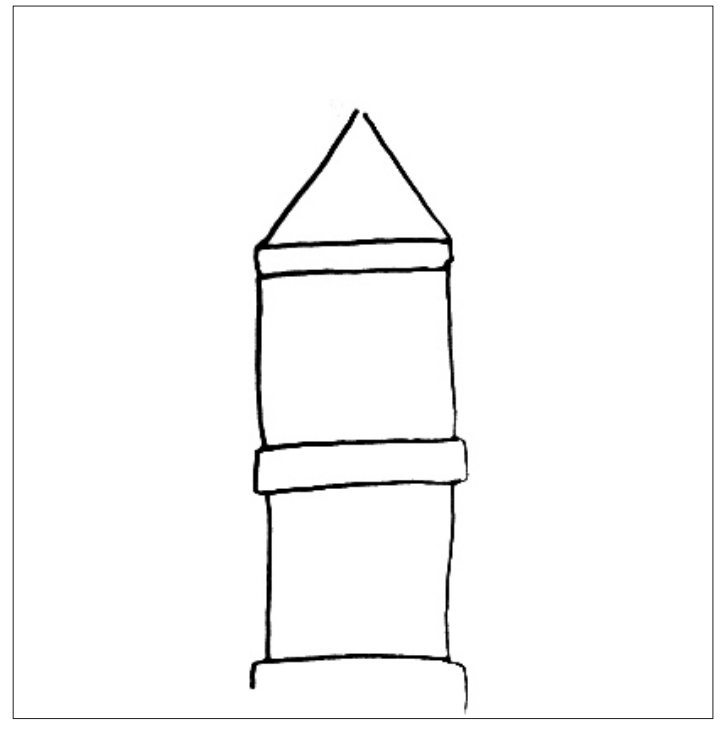

Figura 7. Detalle del monumento grabado sobre el pilar-estela de Monforte del Cid (según Ramos, 1992).

do por el arquitecto (Ramos y Ramos, 1992; Castelo, 1995) supuso la aceptación del significado del monumento turriforme como símbolo de salvación en el área ibérica contestana. Además, la representación grabada de un Nefesh en una de las cuatro caras del pilar-estela no es el único elemento punicizante de que consta: por un lado, la propia estructura del pilar con una decoración de molduras entrantes es idéntica a las llamadas "falsas puertas" tan representadas en la arquitectura funeraria púnica (en monumentos tan conocidos como los de Dougga o Sabratha y en infinidad de estelas funerarias). Por otro lado, la gola que corona el pilar alicantino con una nacela muy volada y cóncava y la decoración de ovas que la enmarca, se encuadra perfectamente en los modelos púnicos estudiados por Lézine (Lézine, 1961) y, más recientemente, por nosotros mismos (Prados Martínez, 2005b, 393). Dentro, pues, de este marco cultural púnico, se puede entender el papel que desempeñó el grabado realizado sobre el pilar-estela ibérico que debió de funcionar como un apoyo más de cara a asegurar la salvación del alma del difunto enterrado bajo él.

\section{LAS REPRESENTACIONES DEL NEFESH SOBRE AMULETOS Y COLGANTES}

La utilización y la producción de amuletos y escarabeos en el mundo fenicio y púnico es uno de los rasgos artísticos más destacados de esta cultura mediterránea, sobre todo en el marco de las artes menores. Además, la 


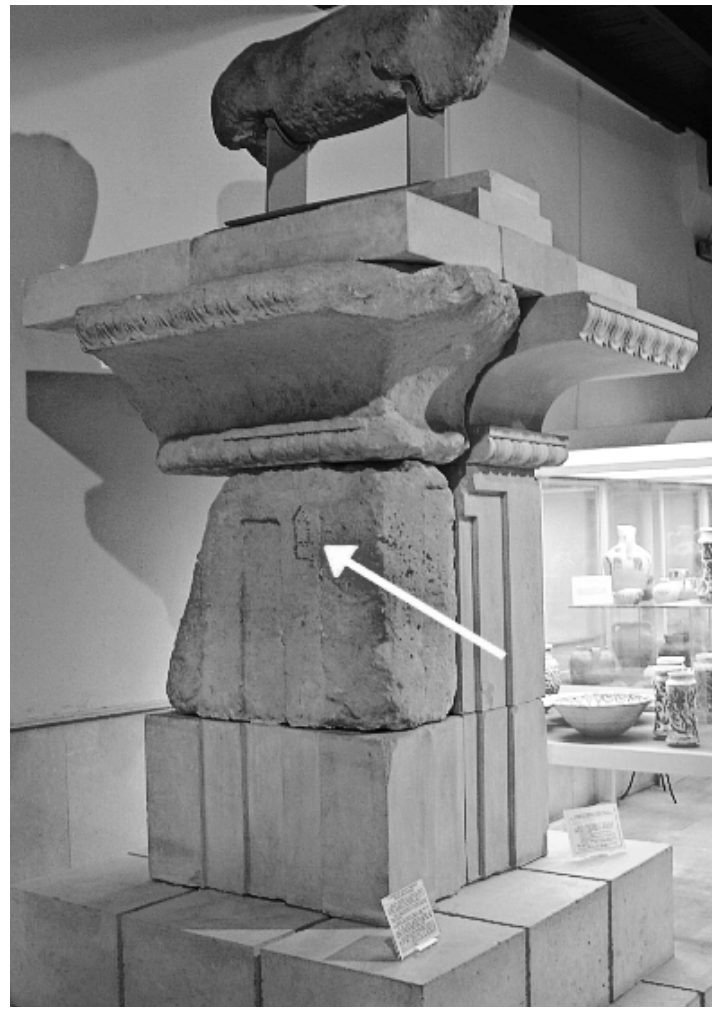

Figura 8. El pilar-estela de Monforte expuesto en el Museo de Elche. La flecha señala la ubicación del grabado. Agosto de 2004.

aparición de los mismos en el interior de los recintos funerarios es una muestra de la importancia que tuvo la magia egipcia, fundamentalmente, en la concepción de ultratumba, en las supersticiones y en las manifestaciones esotéricas. Se ha de tener en cuenta que los amuletos, que imitaban en muchos casos a los de tipo egipcio, fueron tanto importados desde el país del Nilo como copiados en talleres locales. Para algunos autores estas realizaciones indicaron la capacidad de la religiosidad egipcia para incidir con sus valores simbólicos en todo el Mediterráneo antiguo (Acquaro, 1988, 394).

A pesar de que entre todos los tipos de amuletos empleados fue el escarabeo, símbolo de vida eterna y sello de propiedad al tiempo, el modelo que triunfó en los ambientes semitas que estudiamos en este trabajo ${ }^{25}$, nosotros nos vamos a centrar en otros modelos de colgantes y amuletos que se emplearon también con cierta profusión y que han aparecido adornando los cuerpos de los difuntos depositados en los hipogeos funerarios. Otros

${ }^{25}$ Sobre los amuletos púnicos y las influencias egipcias: Vercoutter, J., 1945; Cintas, P. 1946 y Fernández, J.H. y Padró, J., 1982. amuletos zoomorfos y fitomorfos sobre los que no trataremos fueron también utilizados tales como los que representaron cerdos, liebres, leones, perros, halcones, esfinges y colgantes en forma de bellota, realizados en hueso, esteatita, cornalina, cristal de roca y, en algún caso, ónix. Otros representaron divinidades tales como Isis, Bes, Ptah u Horus, buena muestra de la incidencia cultural y religiosa del mundo egipcio citada anteriormente.

En el ambiente púnico hemos de enumerar también los colgantes que representaron partes humanas tales como manos, brazos y pies, temas muy empleados, por otra parte, en las artes mayores (recordemos, por ejemplo, la gran cantidad de representaciones de manos grabadas en las estelas votivas y los cipos funerarios púnicos). Pero de todos los colgantes y amuletos, los que más nos interesan en este momento son aquellos que representaron monumentos turriformes, realizados sobre diferentes soportes, como el oro del colgante conservado en el Museo de Cádiz, la esteatita del colgante expuesto en el Museo Nazionale G.A. Sanna (Sassari, Cerdeña) ${ }^{26}$ o el hueso del colgante-cipo de Villaricos (del Museo Arqueológico Nacional de Madrid). En estas representaciones los amuletos protectores se cargaron, además, de todos los valores simbólicos de los que venimos hablando a lo largo de este artículo.

El colgante del museo de Cádiz ${ }^{27}$ fue encontrado en los hipogeos de la necrópolis gaditana de Punta de Vaca, célebres por ser el lugar donde se halló, el 30 de mayo de 1887, el primer sarcófago antropomorfo. Además, según los datos que se desprenden de los archivos de la Real Academia de la Historia y del propio museo (archivos fotográficos con referencia CA.CA/9/7949/037-41sobre los "Expedientes del hallazgo de tumbas fenicias en desmontes extramuros de Cádiz" de 1892), el amuleto apareció en la misma época, a finales de la década de 1880 y perteneció al ajuar de una de estas tumbas, que fueron fechadas en torno al siglo IV a.C. ${ }^{28}$ El colgante se conservó magníficamente dada la naturaleza del material (ver fig. 9). Se trata de un pequeño ejemplar de 1,7 cm que presenta un monumento bastante canónico con un basamento escalonado dividido en tres con el inferior de mayor tamaño, un remate piramidal y la anilla de sujeción soldada a uno de los laterales. El pequeño colgante se encuentra hoy expuesto en una de las vitrinas del Museo Arqueológico de Cádiz junto a otros amuletos recogidos en las excavaciones de la misma necrópolis.

\footnotetext{
${ }^{26}$ Se trata de un pequeño amuleto de $1,6 \mathrm{~cm}$ realizado en esteatita (Acquaro, E., 1988, 397)

${ }^{27}$ Perea Caveda, A., 1989.

${ }^{28}$ Fechado en el siglo IV a.C. por su contexto funerario, aunque no fue identificado como un Nefesh de las características que estamos estudiando en este trabajo: Perea Caveda, A, 1985 y 1989.
} 


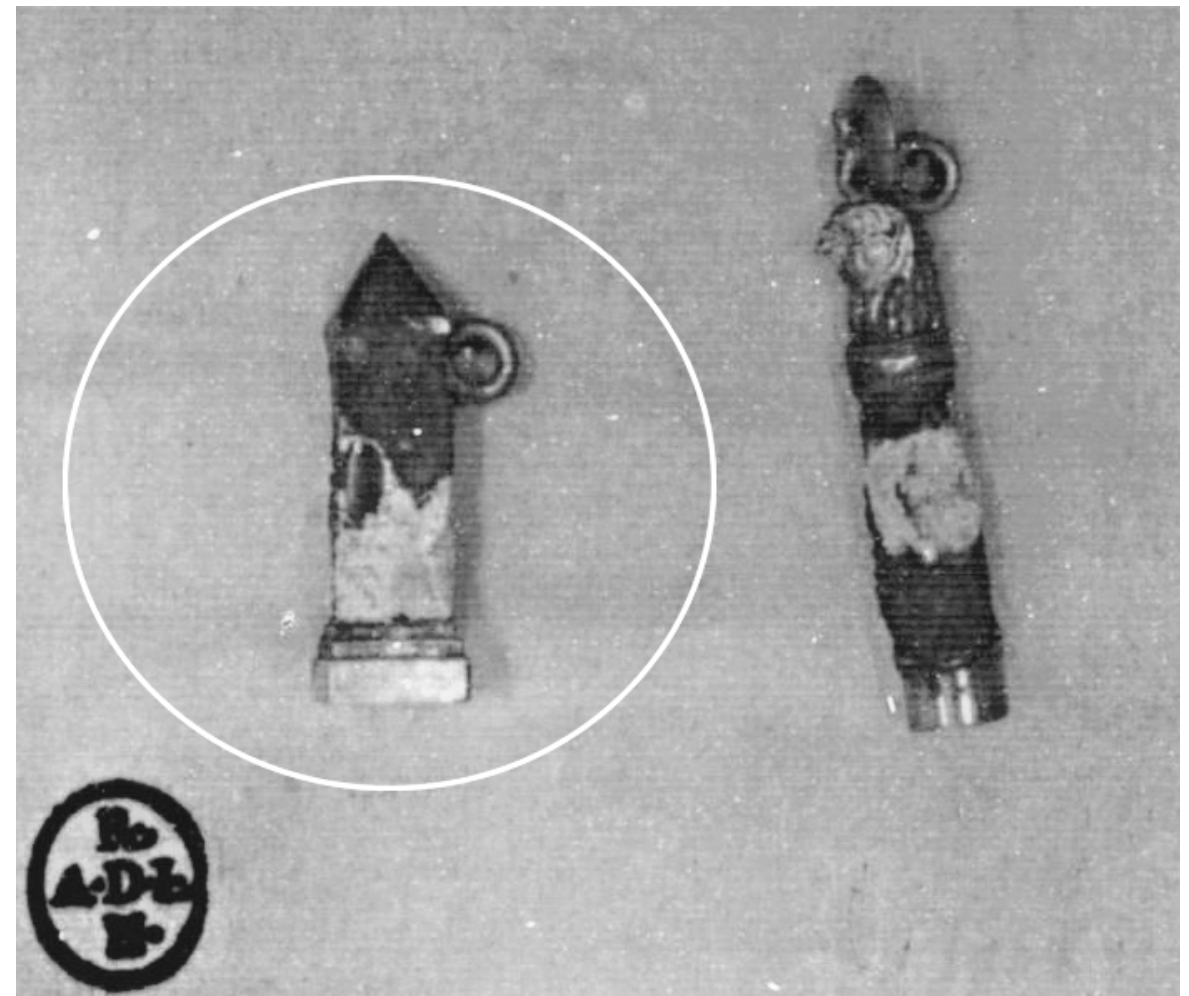

Figura 9.- Amuletos de oro procedentes de Punta de Vaca (Cádiz). A la izquierda, rodeado, el monumento turriforme; a la derecha un bastón con cabeza de Horus. Foto Real Academia de la Historia. Signatura CA.CA/9/7949/037(41).

El ejemplar del Museo Arqueológico de la ciudad de Sassari (Cerdeña) pertenece a un lote de amuletos y plaquitas óseas decoradas expuesto en una misma vitrina. La colección tiene una procedencia dudosa, aunque se cree que fueron encontrados en una necrópolis púnica ubicada en el entorno de la ciudad. Se trata de un colgante mucho más esquemático que el gaditano, debido, fundamentalmente, al material con el que se encuentra realizado, que es esteatita. Mide $1,6 \mathrm{~cm}$ y presenta un monumento alzado sobre podio, con un remate piramidal esquemático y facetado (fig. 10). La anilla de sujeción comparte la misma disposición que en el colgante anterior. La fecha propuesta para esta pieza está bastante poco ajustada (siglos VI-IV a.C.) debido a su descontextualización (Acquaro, 1982, 100). Existen otros ejemplos similares recogidos en Tharros y en otros puntos de la isla mediterránea aunque no presentan tanta similitud con los monumentos turriformes estudiados (Holbl, 1986).

En el caso de los amuletos púnicos en forma de cipo funerario como el de Villaricos (fig. 11) debemos entrar a valorar, también, su similitud con los amuletos egipcios que representaban el Dyed o espina dorsal de Osiris, colocados generalmente entre los vendajes de algunas momias y que simbolizaban la estabilidad, por lo que, de ser así, no representarían estructuras arquitectónicas como tal. En cualquier caso, el colgante de Villaricos conservado en el M.A.N. presenta una estructura muy diferente a los dos citados anteriormente ${ }^{29}$. Al no constar de un remate piramidal, lleva la anilla de sujeción en la parte superior. Este hecho demuestra que en los ejemplos gaditano y sasaritano era fundamental conservar intacta y bien representada la cubierta piramidal de la pequeña estructura, mientras que en el caso almeriense no cabe duda de que se trata de un cipo o pilar, cargado también de contenido religioso, pero que no podemos interpretar como la representación en pequeña escala de un monumento de grandes dimensiones.

Los amuletos fueron piezas que se ubicaron sobre los difuntos tratando de infundirles protección y, según la lectura que se desprende del análisis iconográfico que defendemos en estas líneas, cierta "seguridad" en lo que iba a significar su tránsito hacia el más allá. La talla de pequeños Nefesh en estos colgantes tuvo exactamente la misma motivación que las representaciones pictóricas y escultóricas de los modelos arquitectónicos. Ambos

\footnotetext{
${ }^{29}$ Almagro Gorbea, M.J., 1984.
} 


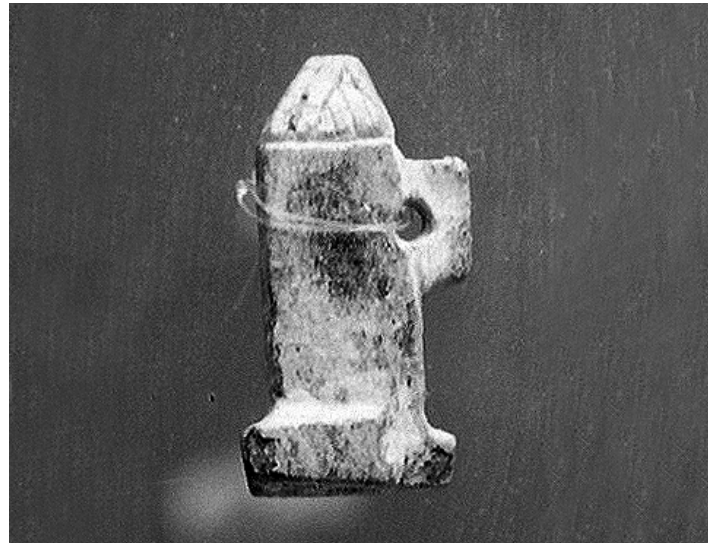

Figura 10. Detalle del colgante de Sassari. Junio de 2005.

soportes son complementarios a la hora de esbozar una interpretación para tratar de explicar el significado de tales representaciones. Gracias a hallazgos como la estela funeraria romana de Cheffia-Tal es fácil comprender la importancia de la representación del modelo arquitectónico y cómo paulatinamente éste se transformó en un símbolo de salvación, ubicado junto con otros reconocidos tales como los caduceos o las coronas de laurel.

\section{CONCLUSIONES}

A lo largo de la exposición hemos puesto de manifiesto la característica polisemia de los modelos arquitectónicos objeto de estudio. En este tipo de construcción convergen simbolismo religioso, rango social y poder político. Como se ha visto, los monumentos turriformes funcionaron como símbolo de salvación, es decir, como medio de expresión de la esperanza de aquellos que, a través de un tipo muy concreto de construcción vertical acompañada de una decoración relacionada con aspectos religiosos, veían en este tipo de arquitectura un vehículo para asegurar la salvación del alma. Por otro lado, los monumentos turriformes fueron ubicados en zonas estratégicas, elevadas, y aisladas con una clara motivación de marca territorial o espacial. Además, a este respecto, hay que añadir la propia estructura arquitectónica que presentaron los edificios, monumental y muy elevada, muy propicia, por lo tanto, para funcionar como una marca de territorio o de la propiedad.

Con la construcción de un monumento de estas características, dedicado a la memoria de un antepasado y su ubicación en un espacio geográfico concreto, nunca elegido al azar, quedaba subrayado el papel de toda la familia en el marco de las relaciones sociales. A través de la heroización y en algún caso, divinización, del personaje en cuestión, quedaban legitimados en sus funcio-

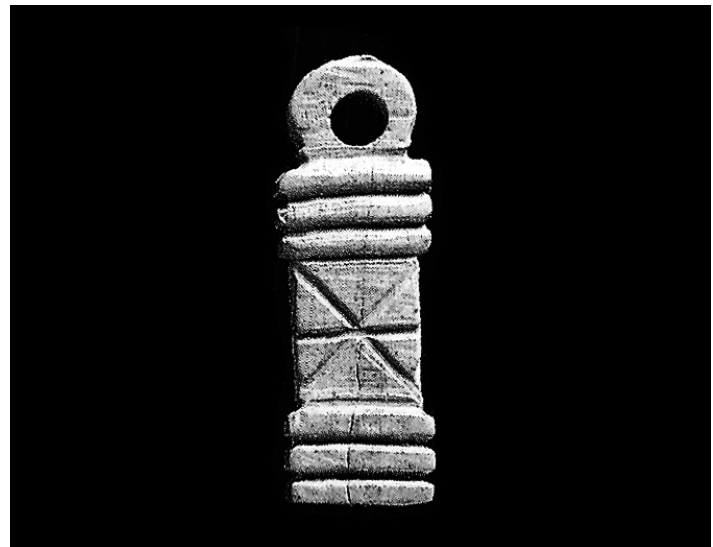

Figura 11. El colgante en forma de cipo de Villaricos conservado en el M.A.N.

nes o en su posición social, a través del monumento, todos sus descendientes. Esta misma cuestión converge con el papel de señalizador territorial: con la construcción de un monumento no sólo se honraba a un miembro de la familia difunto y se legitimaba la posición social del resto de la familia; también se aseguraba el control sobre la propiedad privada a través de un mensaje político, económico y social que emanaba y se emitía desde la propia arquitectura.

En un primer momento, posiblemente a partir del Bronce Final en la región próximo oriental, la edificación de monumentos turriformes supuso la arquitectonización de una idea, de la idea de salvación, plasmada en la construcción de estructuras verticales que ayudaban a la ascensión del alma del difunto y a alcanzar la inmortalidad. Posteriormente, y ya en época púnica (desde el siglo VI a.C.), estos modelos arquitectónicos que se construyeron en el Levante Mediterráneo y en el norte de África púnica obtuvieron, por sí mismos, el valor de símbolo sagrado. Además, tal percepción ideológica fue incluso trasladada por los cartagineses a otras regiones ocupadas por ellos desde mediados del siglo VI a.C., tales como Cerdeña o ubicadas dentro de su área de influencia económica y cultural como la propia Península Ibérica. En el caso peninsular contamos con la aparición del célebre colgante de oro conservado en el Museo de Cádiz que mencionábamos anteriormente y con otro ejemplo, si cabe, más gráfico, ya que no puede ser un elemento importado como el colgante gaditano, como es el de la talla de un monumento turriforme en una de las caras del pilar-estela ibérico de Monforte del Cid (Alicante) que fue, sin duda, como un apoyo más para la salvación del alma del difunto enterrado bajo el pilar o incluso de las almas de los que pudieron estar enterrados alrededor.

No sólo hay que tener en cuenta el valor del símbolo vinculado a la idea de la salvación, también hay que observar en la representación del monumento turriforme 


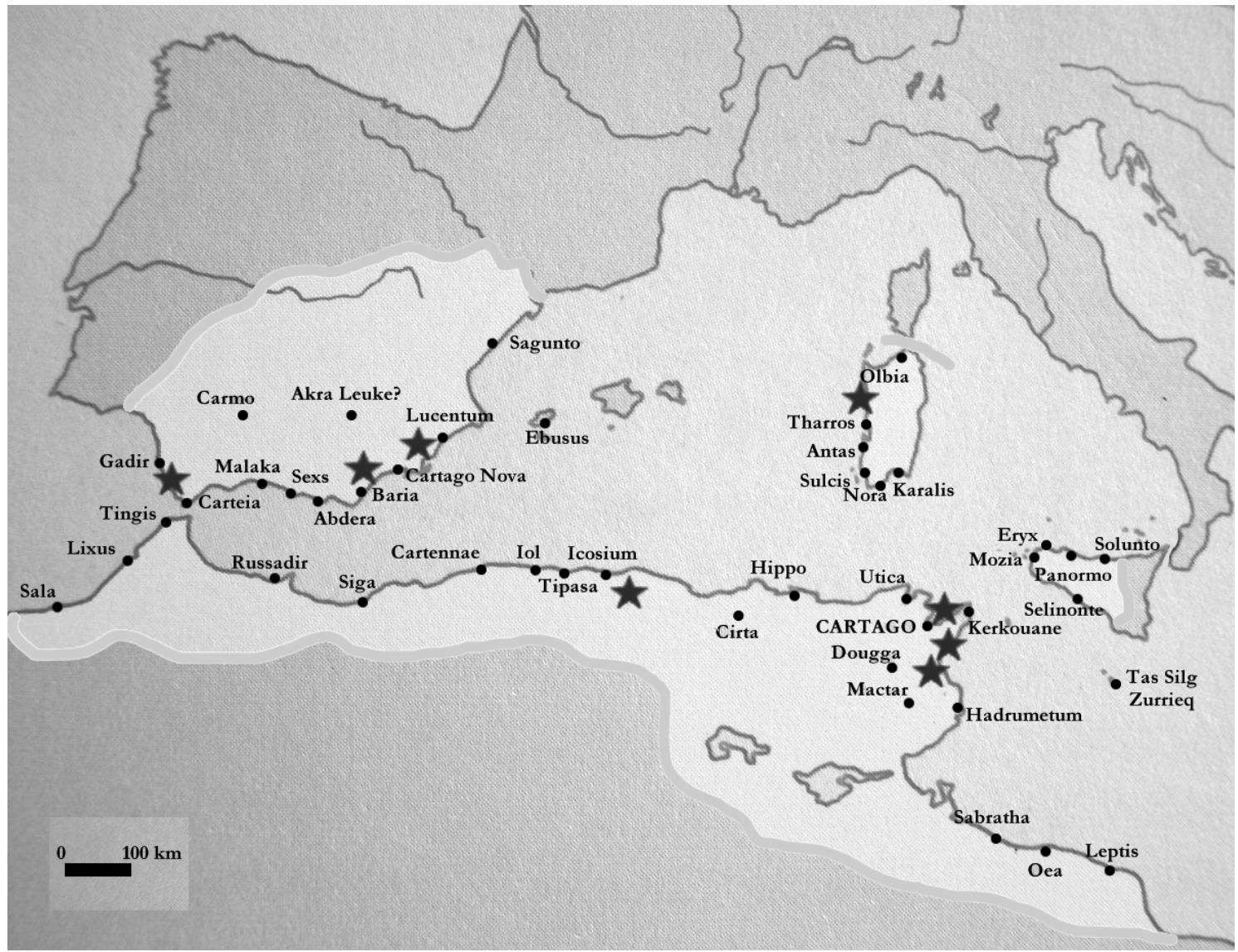

Figura 12. Mapa del Mediterráneo Occidental. Las estrellas señalan los lugares de los hallazgos de los materiales mencionados en el texto.

la idea de protección, de amuleto contra los peligros derivados del tránsito del alma hacia el más allá, surcando el cielo acosado por genios malignos y demonios y atravesando el océano primordial, auténtico elemento purificador de donde los cartagineses entendían que procedían las lluvias, antes de alcanzar la inmortalidad. Esa es la razón de la iconografía que acompañó a la estructura arquitectónica, compuesta de aves, barcos, sirenas, esfinges, deidades aladas, delfines y demás animales marinos y de las decoraciones que, en el interior de las cámaras sepulcrales, fueron representadas junto a los Nefesh. La aparición de animales psicopompos en muchos de los edificios o representados al lado de otros que decoraban las paredes de los hipogeos púnicos se vinculó, por un lado, con el transporte de las almas hacia el más allá y, por otro lado, con los acompañantes del difunto heroizado.

El cotejo de las estructuras arquitectónicas construidas, de algunos de los indicios recogidos en las tumbas, de los amuletos y de algunas decoraciones pictóricas y escultóricas con algunos textos conocidos pertenecien- tes a sociedades vecinas y contemporáneas nos permiten hoy reconstruir, de la manera más fiel posible, cómo entendió la sociedad fenicia y púnica el más allá y la manera de alcanzarlo, salvándose de la condenación. Por otro lado, el problema de las inscripciones funerarias fenicias es que la mayoría de ellas tan sólo mencionan el nombre del difunto y su genealogía, y no aparecen fórmulas que aludan a la necesidad de recordarlo o a la esperanza en el más allá, como cabe esperar de cualquiera de las inscripciones de similares características en el mundo griego. Sí sabemos, a pesar de la exigua información que se puede recuperar de los textos, que para los fenicios y cartagineses la vida de los hombres terminaba con la muerte, aunque el ser, la esencia, no se extinguía del todo ${ }^{30}$. El alma seguía una existencia incómoda que exigía de los vivos ciertos cuidados y atenciones, visibles en los objetos de ajuar y en las deposiciones de ofrendas (alimentos, bebidas, amuletos y objetos

${ }^{30}$ Ribichini, S. y Xella, P., 1994 
de uso cotidiano). Todo apunta a que el bienestar del alma del difunto (del alma que residía en la tumba) dependió en gran medida de los cuidados y atenciones prestados por sus familiares. De esa relación dependía, además, que el alma del difunto fuese beneficiosa para la familia o supusiera una amenaza terrible ${ }^{31}$.

En algún caso, como hemos mencionado, se ha manifestado erróneamente que la aparición de monumentos turriformes pintados en el interior de las cámaras sepul-

${ }^{31}$ Que junto con los alimentos incluían todo tipo de talismanes para evitar que las almas fueran disturbadas en modo alguno: Ribichini, S. 2004, 58. crales estaba relacionada con la imposibilidad por parte de las familias de los difuntos allí enterrados de construir -por motivos económicos- un monumento como tal, por lo que se veían obligados a representarlos pintados, como un acto simbólico. Con los datos que se manejan hoy y partiendo del análisis del monumento funerario en cualquiera de sus ejecuciones o realizaciones, arquitectónicas, pictóricas o escultóricas, hemos de ir más allá y comprender que, con el paso de los siglos, el Nefesh se convirtió en un símbolo sagrado que podía transmitir una serie de valores, poderes y privilegios por igual, fuese una estructura de sillares de seis metros de altura o un pequeño colgante de hueso de apenas un centímetro.

ANEXO: Corpus de representaciones parietales de monumentos turriformes en el área de Cartago

\begin{tabular}{|c|c|c|c|c|}
\hline LUGAR & $\begin{array}{c}\text { MOTIVOS } \\
\text { DECORATIVOS }\end{array}$ & $\begin{array}{l}\text { TIPO DE } \\
\text { TUMBA* }\end{array}$ & $\begin{array}{l}\text { TIPO DE } \\
\text { DECORACIÓN }\end{array}$ & CRONOLOGÍA \\
\hline $\begin{array}{l}\text { El Mansourah } \\
\text { (Kélibia, Túnez) }\end{array}$ & Monumentos turriformes & Hipogeo & $\begin{array}{l}\text { Pictórica al exterior y al } \\
\text { interior de la tumba }\end{array}$ & IV-III a.C. \\
\hline $\begin{array}{l}\text { Korba, hipogeo } \\
\text { de Ksar es-Saad } \\
\text { (Túnez) }\end{array}$ & $\begin{array}{l}\text { Vegetales (palmeras y palmas), } \\
\text { geométrica, monumento } \\
\text { turriforme sostenido por } \\
\text { dos signos de Tanit }\end{array}$ & Hipogeo & Pictóricas y grabados & III a.C. \\
\hline $\begin{array}{l}\text { Arg el-Ghazzouani } \\
\text { (Kerkouane, Túnez) }\end{array}$ & $\begin{array}{l}\text { Monumento turriforme, } \\
\text { decoraciones geométricas, } \\
\text { signos de Tanit, símbolos } \\
\text { apotropaicos }\end{array}$ & Hipogeo & Pictórica & IV-III a.C. \\
\hline $\begin{array}{l}\text { Djebel Mlezza } \\
\text { (Kerkouane, Túnez) }\end{array}$ & $\begin{array}{l}\text { Monumentos turriformes, } \\
\text { altares, ciudad amurallada, } \\
\text { aves, decoración geométrica. } \\
\text { Signos de Tanit y signos } \\
\text { apotropaicos }\end{array}$ & Hipogeo & $\begin{array}{l}\text { Pictórica (óxidos de hierro y de } \\
\text { manganeso) }\end{array}$ & IV a.C. \\
\hline $\begin{array}{l}\text { El Guetma (Oued } \\
\text { Sejnane, Túnez) }\end{array}$ & Monumento turriforme & Hipogeo & Pictórica (ocre ferruguinoso) & IV a.C. \\
\hline $\begin{array}{l}\text { Réjiche (Mahdia, } \\
\text { Túnez) }\end{array}$ & Monumento funerario & Hipogeo & Pictórica & IV-III a.C. \\
\hline $\begin{array}{l}\text { Djebel Zabouj } \\
\text { (Hédils, Túnez) }\end{array}$ & $\begin{array}{l}\text { Monumentos turriformes, } \\
\text { aves, prótomos equinos, } \\
\text { signos apotropaicos }\end{array}$ & Hanout & $\begin{array}{l}\text { Pictórica (ocres vegetales, } \\
\text { óxidos férricos) }\end{array}$ & V-IV a.C. \\
\hline $\begin{array}{l}\text { Sidi bou Aziz } \\
\text { (Mogods, Túnez) }\end{array}$ & Monumento turriforme & Hanout & Grabado en torno a un nicho & III a.C. \\
\hline Ben Yasla (Hédils) & $\begin{array}{l}\text { Escena de caza, monumento } \\
\text { turriforme }\end{array}$ & Hanout & Pictórica & IV - III a.C. \\
\hline $\begin{array}{l}\text { Sidi Ali Jebali } \\
\text { (Cabo Bon, Túnez) }\end{array}$ & Monumento turriforme, altar & Hanout & Grabado en la pared posterior & III a.C. \\
\hline $\begin{array}{l}\text { Monforte del Cid } \\
\text { (Alicante) }\end{array}$ & Monumento turriforme & $\begin{array}{l}\text { Pilar-estela } \\
\text { ibérico }\end{array}$ & Grabado en una de las caras & IV-III a.C. \\
\hline
\end{tabular}

* Hanout indica que se trata de una tumba de cámara líbica e hipogeo de una púnica 


\section{BIBLIOGRAFÍA:}

ACQUARO, E.

1982: "La collezione punica del Museo Nazionale

"Giovanni Antonio Sanna" di Sassari. Gli amuleti". Rivista di Studi Fenici, 10, suppl. Roma; pp. 1-46. 1988: "Amuletos y escarabeos". En MOSCATI, S. (Dir.) Los Fenicios, Barcelona; pp. 394-403

ALMAGRO GORBEA, M. (1982): "Pozo Moro y el influjo fenicio en el periodo orientalizante de la Península Ibérica". Rivista di Studi Fenici, X, Roma; pp. 231-272

ALMAGRO GORBEA, Ma . J. (1984): Orfebrería fenicio-púnica del Museo Arqueológico Nacional, Madrid.

AMADASI GUZZO, M.G. y EQUINI SCHNEIDER, E. (1997): Petra, Milano.

BABELON, E.; CAGNAT, R. y REINACH, S. (1892): Atlas Archéologique de la Tunisie. $1^{\mathrm{eme}}$ Serie. París.

BARROIS, A. G. (1953): Manuel d'archéologie biblique, II, Paris

BISI, A. M. (1978): "Elementi vicino-orientali nell'arte punica". Atii del $1^{o}$ Convegno Italiano sul Vicino Oriente Antico, Roma; pp. 129-148

BONNET, C.; LIPINSKI, E. y MARCHETTI, P. (Eds.) (1986): Religio Phoenicia. Studia Phoenicia IV, Bruxelles.

CAGNAT, R. y MERLIN, A. (1914-1926): Atlas Archéologique de la Tunisie. $2^{\mathrm{eme}}$ Serie (1/100.000). Paris.

CAGNAT, R. y REINACH, S. (1886): "Exploration de la Vallée supérieure de l'Oued Tin”. Bulletin Archéologique du Comité des Travaux Historiques et Scientiphiques. Paris; pp.99-120.

CAMPS, G. (1961): Aux origines de la Berberie. Monuments et rites funéraires protohistoriques, Paris.

CASTELO RUANO, R. (1995): Monumentos funerarios del Sureste Peninsular: Elementos y Técnicas Constructivas, Madrid.

CID PRIEGO, C. (1949): "El sepulcro de torre mediterráneo y sus relaciones con la tipología monumental", Ampurias 11. Barcelona; pp. 91-126

CINTAS, P. (1946): Amulettes puniques, Túnez.

CINTAS, P. y GOBERT, E. G. (1939): "Les tombes puniques du Jebel Mlezza". Revue Tunisienne, T. XXXVI, 1939, Tunis; pp. 135-198

COARELLI, F. y THÉBERT, Y. (1988): “Architecture funéraire et pouvoir: réflexions sur l'hellénisme numide". Mélanges de l'École Française de Rome et Athénes, 100. Roma; pp. 761-818

DEYROLLE, E. (1903): "Annotation à l'Atlas archéologique de Tunisie I. Feuille de Grombalia". Bulletin de la Société Archéologique de Sousse, T. I. Sousse; pp. 154-159
DUSSAUD, R. (1935): "La notion d'âme chez les israélites et les phéniciennes", Syria XVI. Paris; pp. 267-277.

FANTAR, M. (2002): “Tombe aux tanits porteurs d'un mausolée". Africa, Serie REPPAL, Revue des Etudes Phéniciennes et Puniques et des Antiquités Libyques XII. Institut National du Patrimoine, Tunis; pp. 47-56

FANTAR, M. H.

1970: Eschatologie phénicienne et punique. Collection notes et documents, Tunis.

1985: “L’Archéologie punique au Cap Bon. Découvertes récentes. Rivista di Studi Fenici, XIII, 2, Roma; pp. 211-221.

1988: "La décoration peinté dans les tombes puniques et les haouanets libyques de Tunisie". Africa, X, Tunis; pp. 28-49

1998: Kerkouane. Cité punique au pays berbère de Tamezrat, Tunis.

FERNÁNDEZ, J. H. y PADRÓ, J. (1982): Escarabeos del Museo Arqueológico de Ibiza, Madrid.

FERCHIOU, N (1988): "L'architecture prérromaine de Uzali Sar". Africa, Serie REPPAL, Revue des Etudes Phéniciennes et Puniques et des Antiquités Libyques IV . Institut National du Patrimoine. Tunis; pp. 216217.

GAMER, G. (1982): "Sepulchrum Cnei et Publ. Cornel. Scipionum". Das Monument bei Tarragona und andere Bauten in der Nachfolge des Maussolleion von Halikarnass". Madrider Mitteilungen, 23. Madrid; pp. 296-317

GHAKI, M. (1999): Les Haouanet de Sidi Mhamed Latrech, Tunis.

HOFTIJZER, J. , JONGELING, K. (1995): Dictionary of the North-West Semitic Inscriptions, Leiden.

HOLBL, G. (1986): Ägyptisches Kulturgut im phönikischen und punischen Sardinien, Leiden.

IZQUIERDO PERAILE, I.

1999: "Parejas de esfinges y sirenas en las necrópolis ibéricas: una primera aproximación al tema". Actas II Congreso de Arqueología Peninsular (Zamora, 1996). Volumen III, Madrid.

2000: Monumentos funerarios ibéricos: Los pilaresestela. Serie de Investigación Prehistórica. Diputación Provincial de Valencia, Valencia.

KAI: DONNER, H. y RÖLLIG, W. (1971): KAI. Kanaanäische und Aramäische Inschriften. Wiesbaden.

KRANDEL-BEN YOUNES, A. (2002): La présence punique en pays Numide, Tunis.

$K T U$ : DIETRICH, M.; LORETZ, O. y SANMARTÍN, J. (Eds.) (1995): The Cuneiform Alphabetic texts from Ugarit. Rabs ibn Hani and others places, Münster.

LEHNER, M. (2003): Todo sobre las pirámides, Barcelona. 
LÉZINE, A. (1961): Architecture punique. Recueil de documents, Tunis.

LLOBREGAT, E. (1994): "Tradición religiosa feniciopúnica en Contestania”. El mundo púnico. Historia, Sociedad y Cultura, Murcia; pp.169-175

LODS, A. (1906): La croyance à la vie future et le culte des morts dans l'antiquité israèlite, Paris.

LONGERSTAY, M.

1993: "Representation de mausoleés dans les haouanet de la Tunisie". Antiquités Africaines, 29, Paris; pp. 17-51

1995: "Les représentations picturales de mausolées dans les haouanet du nord-est de la Tunisie". Actes III Congrès International des Études Phéniciennes et Puniques. Tunis, 1991. Volumen II, Tunis; pp. 210-219

LÓPEZ DE LA ORDEN, Ma. D. (1994): "La glíptica fenicia y púnica en el sur peninsular". El Mundo Púnico. Historia, Sociedad y Cultura, Murcia; pp. 387-394.

MANSUELLI, G. A. (1963): "Monumento Funerario". En Enciclopedia dell' Arte Antica Classica e Orientale, Vol. V. Roma; pág. 171

MAZZA, F. (1975): "Le formule di Maledizione nelle iscrizioni funerarie e votive fenicie e puniche". Rivista di Studi Fenici III, Roma; pp. 19-30.

OLMO LETE, G. DEL, SANMARTÍN, J. (1996/2000): Diccionario de la lengua ugarítica, Aula OrientalisSupplementa, II vols., Sabadell.

PEREA CAVEDA, A.

1985: "La orfebrería fenicio-púnica de Cádiz". Aula Orientalis, 3, Sabadell; pp. 295-322.

1989: “Cádiz: orfebrería fenicia". El oro en la España Prerromana, Revista de Arqueología número extra, Madrid: 58-67

PICARD, C. (1973): "La conception du mausolée chez les puniques et chez les numides". Rivista di Studi Fenici I, Roma; pp. 31-35

PICARD, G.CH. (1957): Les Religions de l'Afrique Antique, Paris.

POINSSOT, C. y SALOMONSON, J.W. (1963): "Un monument punique inconnu: le mausolée d'Henchir Djaouf d'après les papiers inédits du Comte C. Borgia". Oudheidkundige Mededelingen, XLIV, Leiden; pp. 71-84.

PRADOS MARTÍNEZ, F.

2001: "La democratización de la muerte en el mundo púnico. Las necrópolis de Kerkouane (Túnez)". Revista de Arqueología, no 241, Madrid; pp. 28-39.

2005a: "Memoria del Poder. Los monumentos funerarios ibéricos en el contexto de la arquitectura púnico-helenística". Actas del Seminario Casa de Velázquez-Universidad Autónoma de Madrid. Cuadernos de Prehistoria y Arqueología de la Universidad
Autónoma de Madrid, $n^{o}$ 28-29 (2002-2003), Madrid; pp. 203-226

2005b: Aproximación al estudio de la arquitectura púnica a través del análisis arqueológico de los monumentos funerarios. Tesis Doctoral, Universidad Autónoma de Madrid.

2005c: "La Beatitud Divina: una ideología oriental clave para el desarrollo de la arquitectura monumental púnica”. El Periodo Orientalizante en la Península Ibérica. Anejos AEspA, XXXIII, Madrid; pp. 635-649

RAKOB, F. (1979): "Numidische Königsarchitektur in Nordafrika”. En HORN, H. G. y RÜGER, C. B. (Eds.) Die Numider. Bonn; pp. 119-171

RAMOS FERNÁNDEZ, R. y RAMOS MOLINA, A. (1992): El Monumento y el Temenos ibéricos del Parque de Elche, Elche.

RAMOS SÁINZ, M.L. (1986): Estudio sobre el ritual funerario en las necrópolis fenicias y púnicas de la Península Ibérica, Madrid

RIBICHINI, S.

1987: "Concezioni dell'oltratomba nel mondo fenicio e punico". En Archeologia dell'Inferno, Verona; pp. 147-161

1988: "Creencias y vida religiosa". En MOSCATI, S. (Dir.) Los Fenicios, Barcelona; pp. 104-125

2004: "Sui riti funerari fenici e punici. Tra Archeologia e storia delle religioni”. En González Prats, A. (Ed.), El mundo funerario. Actas del III Seminario Internacional sobre Temas Fenicios, Guardamar, 2002, Alicante: 43-76.

RIBICHINI, S. y XELLA, P. (1994): La religione fenicia e punica in Italia, Roma.

STTUCHI, S.

1985: "Il monumento funerario rappresentato su una stele di Sactut". Histoire et Archéologie de l'Afrique du Nord. Actes du II Colloque International, Grenoble, 1983, Paris; pp. 499-504

1987: 'L'Architettura funeraria suburbana cirenaica, in rapporto a quella della chora viciniore ed a quella Libya ulteriore, con speciale riguardo all'età ellenistica". Quaderni di Archeologia della Lybia, XII, Roma; pp. 249-377

TOYNBEE, J.M.C. (1993): Morte e sepoltura nel mondo romano. Roma.

TRIEBEL, L. (1999): "Die Nefaschot, Herkunft, Vorkommen und Bedeutung einer frühjüdischen Grabsmalsgattung, verarbeitet aus archaölogischen und literarischen Quellen". Magisterarbeit im Fach Judaistik, Berlin.

VERCOUTTER, J. (1945): Les objets égyptiens et égyptisants du mobilier funéraire carthaginois, Paris.

WALTER, C. (2003): "Sur les origines iconographiques de la sirène en Grèce ancienne: des hypothèses 
avancées depuis un siècle aux dernières découvertes". En IZQUIERDO, I. y Le MEAUX, H.: Seres Híbridos, Madrid; pp. 261-289

XELLA, P. (1997): (Ed.) Archeologia del Inferno, Verona.
ZISSU, B. (2005): "A burial cave with Greek graffiti at Khirbat-el 'Ein, Judean Sephelah”. Atiqot, 50, Jerusalem; pp. 27-36.

Recibido el 26-04-06 Aceptado el 13-06-06 